\title{
Comparing Cultures in Southern Ethiopia: From Ethnography to Generative Explanation
}

\section{Jon G. Abbink}

African Studies Center, Leiden, and Vrije Universiteit, Amsterdam, Netherlands

This special issue of Northeast African Studies is an exercise in comparative ethnography and theoretical exploration. It starts with the following question: Why is there such remarkable regional diversity in the cultural traditions and modes of life in the societies of southern Ethiopia, and with what kind of theoretical and ethnographic understanding can we explain it? The question has often been posed as to what extent these small-scale societies with their notable linguistic commonalities (being of the Omotic, Cushitic, and Surmic language families and thus per group suggesting a common "origin") have shared social and economic traits, political institutions, ideologies, and ritual complexes, and what has generated their paths of differentiation.

Apart from evoking fascinating ethnographic questions, this issue also raises theoretical problems, of wider significance outside the Ethiopian ethnographic context, related to structural comparison, societal change, and the import of underlying ecological and socioeconomic factors or processes that fuel cultural differentiation. Regional comparison is a well-established research tradition in anthropology and has many forms. There is the school of statistical comparison and correlation, going back to the now largely ignored work of Harold Driver and his group (Driver 1973; Jorgensen 1974), and which is partly continued in the electronic journal World Cultures and in the large number of studies of the Human Relations Areas Files at Yale University. The work of

๑ Northeast African Studies (ISSN 0740-9133)

Vol. 7, No. 3 (New Series) 2000, pp. 1-14 
C. Lévi-Strauss on American Indian mythology is another form, marked not only by erudition and controversial comparisons, but also by inspiring research questions about the workings of the human mind and the properties of "culture" as an abstract system or human predisposition. For many "classical" areas of anthropological theorizing, like Papua New Guinea/Melanesia, southern Africa, Sudan, and Indian South America, there has emerged a host of publications on regional-structural comparison (for some examples, see Barth 1975, 1987; Kuper 1982; Rivière 1984; Barnard 1992; Simonse 1992; Knauft 1993). Remarkably, Ethiopia, a country of much internal variety yet with a notable history of intergroup relations and a basis of similarities in cultural traditions, has lagged behind as a domain of study and has not been prominent in the international debate (except of course in the realm of paleoanthropology). While several authors have already called for such a comparative effort, the work done on cultural traditions in Ethiopia and adjacent regions has been fairly limited, and often the attempts made can only be found in monographs on certain ethnic groups or culture areas aiming to place them in a wider regional setting. ${ }^{1}$

This volume, the result of a pioneering workshop in Oxford in 1999 organized by D. Freeman and E. Watson (then of the London School of Economics and Political Science and of Cambridge University), tries to restart the discussion in a more concentrated manner (see Freeman's "Introduction" below), somewhat analogous to previous efforts like, e.g., A. Kuper's "regional comparison" approach (1982) on southern Africa, although with more eye to agency and praxis. It goes without saying that this kind of comparative study must be based in solid ethnography, and there is indeed plenty of it in this special issue. But the empirical fact that many "customs," kinship patterns, religious ideas, and rituals are shared and were even partly exchanged among southern Ethiopian groups points to the fascinating transgroup connections that must be explored in a more theoretical and systematic fashion.

The study of the above themes allows scholars to combine historical, structuralist, and agency-oriented approaches. For instance, a study of the cosmologies and worldviews of people in the south reveals that the role of "dual structures" in this culture area is remarkable, referred to by Donham in his analysis of the Omotic-speaking Maale, and already the 
subject of study since the findings of the German Frobenius Institute expeditions in Ethiopia of the 1930s and 1950s (Jensen 1953; Straube 1957; see also Orent 1970 and Almagor 1989) and the work on Oromo social structures (e.g., Haberland 1963; Hinnant 1989). Also among Surmic-speaking agro-pastoral groups, such as the Bodi, Tishana (Abbink 1992b), and Suri, dual clan orders and, in one case, moieties are found as conscious structures. These structural representations of opposition or pairedness are used to organize society, ritual, and historical self-reflection, but can also become elements in a modern discourse of group relations.

The southern Ethiopian research experience confirms what has been accepted in anthropology in the last twenty-five years already: that "ethnic groups" and "culture" are cumulative historical constructions, and evolve not in isolation but in interaction, often within a regional or wider political-economic network. This statement implies that there is no primordiality to be ascribed to "ethnicity" except at the danger of reifying difference, and essentializing "culture" (including language). This does not mean that the cultural complexes and ethnic identities referred to by people and elaborated in ritual, world-view, and values have no meaning or are arbitrary bricolages of cultural material. On the contrary, they are a rich source of belonging and group-esteem and show a measure of internal cohesion. But they are dynamic and changing. They cannot be pinned down only to criteria like language, a common territory, a common "psychological make-up," whatever that is, or shared economic life.

In view of this dynamic character, much more work is needed on the historical-evolutionary processes of differentiation, assimilation, and mutual influencing that have occurred, and still do occur. This diversity in cultural traditions and especially languages is itself an evolutionary, adaptive outcome of the relative isolation or self-containedness of groups in the past millennia. It is modified by contemporary economic processes, and by the modern bureaucratic state which registers, documents, and administratively immobilizes "ethnic difference" between groups and cultures, and thereby essentializes group distinction (cf. Herzfeld 1992 making a similar argument in the context of Europe and its bureaucratic structures). 
Stories of people migrating to and assimilating into other groups and taking up their identity are now scarce. However, during my fieldwork I traced quite a number of immigrants among the southwest Ethiopian Suri through their family histories, but these were to all intents and purposes "Suri" and did not know what I meant when (in the beginning, before I felt the embarrassing tone of the question) I asked what the "ethnic group" of their ancestors was. There was a much more territorial than "ethnic" idea of group belonging. ${ }^{2}$ Apart from the fact that the concept of "assimilation" itself needs rethinking, the openness of local societies to the influx of others is now seriously reduced, especially with the current political system in Ethiopia (and elsewhere). This in itself is a disturbing fact and has already had baneful effects on group relations and cross-group intermarriage. In southern Ethiopia these days, if you are a Sheko or Anuywa or Dizi or Suri, you will remain one-you even have to remain one-till the end of your days.

What these analyses below also restate-following a line of argument in contemporary anthropology-is the concept of culture (cf. Kuper 2000). Again we demonstrate here that the existence of distinct cultures as vessels or containers of meaning specific to one group of people only, as ontological entities, is fallacious. While cultural traditions can be discerned and show a measure of coherence and durability over time, because they are shared, transmitted, and internalized by people, they are not like "natural species," but dynamic, open-ended systems. The point here, however, is that these traditions, as repertoires of meaning, have a content and a relative amount of identity and consistency that set them apart from others. While not retracting theoretically from the currently widely accepted view of the dynamic character of ethnicity (though this is usually denied by political authorities), we want to call for investigating and respecting the actually existing cultural traditions and the views of local people who live with them. Dena Freeman's "Introduction" below elaborates more on the core elements that figure in comparative discussions on southern Ethiopian cultures.

All contributions in this volume are based on original fieldwork, done in the late 1990s and afterwards. ${ }^{3}$ Research findings in most of the papers substantiate the underlying unity of southern Ethiopia as a complex cultural system of exchange and mutual influence. While some 
delve into a particular cultural tradition to explore ideas of variation and cultural difference (Donham, Strecker), others compare across space, among neighboring groups known to have historical links and current patterns of interaction (Freeman, Wood, De'a, Tadesse). In the last contribution to this volume, Gideon Cohen, in a quite original paper, reflects on language policy in the Southern Region, addressing the implications of education policy, language use, and group identification. He provides a link between the analysis of the local and the national level, which will have to be explored in future anthropological research on cultural variation and change in the Ethiopian southwest. His conclusion that ethnic group identity and language identity are not coterminous is very important and underlines a point that anthropologists have asserted over and over again on the basis of solid research, as against the policy makers.

Theoretical approaches used by the authors in this volume are varying, but the nature of the subject of cultural variation and regional comparison implies an extra emphasis on ideas and their itineraries (or their "epidemiology," as D. Sperber [1986] would say): how are ideas adopted, spread, and made successful? Donham seems to stress an approach combining ideational and material processes; Ivo Strecker, in his contribution on the genius loci of Hamar, offers an interesting and innovative view, emphasizing a rhetorical approach to cultural phenomena, which sees the constitution of "reality" as inextricably linked to its rhetorical performance. In some crucial respects he follows Stephen Tyler, a prominent postmodernist thinker in the field of anthropology and linguistics. The approach is quite fascinating and original but also evokes critical responses. Marvin Harris (1994, 65-66) rejects the postmodern viewpoint underlying it because of its relativist and "anti-science" implications, and calls for a rethinking of serious scientific explanations of observed human social life, ${ }^{4}$ i.e., implying a renewed attention to material processes and infra-structural determinants. But a rhetorical approach, in the stimulating way Strecker has elaborated it, is empirically revealing and calls attention to the partly discursive formation of social and cultural phenomena. At the same time, the underlying question should always be how people's agency links ideas and discourse with practices: why and how are ideas, rhetorical strategies, customs, ritual 
elements, etc., taken up and accepted, and how do they redirect social practice? This calls for attention to the sometimes determining and constraining impact of structures of power, economic exchange, inequality, and political domination, beyond the attention to human individual inventiveness and rhetorical and symbolic versatility.

Some authors, like F. Barth in his seminal contributions to ethnography and theory, have tried to develop a "generative approach" to processes of cultural change and variation (Barth 1987, 2002): identifying the structuring principles underlying those processes, and the basis on which people are able to elaborate varieties. For instance, his work on the Mountain Ok identified definite, causal links between social organization and cult forms among these people (1987, 55, 61). This approach also touches upon a related debate on the use of history in anthropology. Cultural elaborations and variations are the result of cumulative historical transformations in territorial groups and their material and ideational modes of adaptation. In an earlier line of debate, the American anthropologist Marshall Sahlins has contributed to such an approach, unleashing a controversial, and therefore fruitful and productive, debate (e.g., with G. Obeyesekere 1992) on cultural change and structural history (Sahlins 1985, 1995, 1999), while Emiko OhnukiTierney edited an influential collection on Culture Through Time (1990).

The study of cultural variation across space and time within broad cultural traditions or "traditions of knowledge" (Barth 1987) poses a number of methodological challenges. Actual differences in cultural details and divergent historical processes are easily summed up, but how is one to develop explanatory accounts or models, on the basis of which empirical details, and in what theoretical perspective? Should more formal model building be the goal, including the coding of elements in computer models? Should a political-economy approach be pursued, which might account for the emergence and reproduction of inequality on the basis of surplus extraction and power difference? Should prime attention be given to the inventive individuals that create variation and change? Barth's question (1987, see also his recent Mintz lecture [2002]) was about what the generative mechanisms of variation were: the causally active patterns and elements in the social and economic 
organization of societies that tend to "produce" variation, innovation, and alternative forms on the basis of similar cultural materials or traditions of knowledge. This comparative effort has been central in much of anthropology since E. B. Tylor's pioneer work of the 1870s, but has recently been regaining a good deal of attention (see for instance Gingrich and Fox 2002). Several of the papers below address the issue of what generates variation. In future comparative work, a concern with generative mechanisms, as observed causal tendencies in sociocultural phenomena and human patterns of action, will probably become much more central. ${ }^{5}$

A significant factor that is reshaping local cultures and group relations in Ethiopia and elsewhere is state policy. Indeed, the policy and surveillance of the modern bureaucratically oriented state, even when less efficient or failing in Africa, has set a new discourse of control and regulation, thereby recreating identities and group relations. This was already the case in Ethiopia's imperial days, and it continued in disastrous form under the Derg regime. Although it takes considerable thought to perceive their positive impact, since 1991 radical changes in the administrative structure and the political outlook of the country's new elite have had a qualitatively different, far-reaching effect on the societies and groups described here. One remarkable fact is the notable increase in political insecurity, group tensions, and "ethnic clashes" all across the south (numerous reports in the local Ethiopian press, but see also Abbink 1993; Popp 2001; Young 1999; Tronvoll 2001; Donham et al. 2002). This political dynamic will change people's self-perceptions as they are inexorably, and in a way naively, drawn into the prevailing ethnicist state discourse in Ethiopia. One instance among many is the emerging rift between the Gamo peoples and the Wolaitta, because of new district boundaries and the forced language policy of the central government. ${ }^{6}$ These recent problems are also discussed in Data De'a's paper.

Relatively little addressed in this volume are problems of social and political change, especially those related to processes of "globalization." This is because, firstly, cultural complexities, the nature of which is underestimated time and again by outsiders, not in the least by state agents and donor country NGOs, have to be addressed in their own right, without 
subsuming them immediately under a discourse of change. Secondly, such processes are not (yet) very prominent in the Ethiopian south. Thirdly, we want to discourage the idea prominent in the work of some authors on globalization that all cultural differences are somehow a result of processes of hidden or overt globalization. Finally, we think that the globalization discourse still lacks convincing theories beyond the descriptive level. If it is not over-determined by an economist discourse, it seems to boil down a neo-diffusionist approach that tends to gloss over existing and historically evolved cultural traditions. As said, we feel they should be studied on their own terms and internal dynamics, rather than be pressed into a preconceived framework of globalizing structures. A general theory on the specifics of interaction between local and global factors is difficult to develop, although in many empirically based studies the two levels have been successfully brought together (e.g., Geschiere and Meyer 1999; Nash 2001; Piot 2000; on southern Ethiopia, Pankhurst 2000).

Nevertheless, we do not doubt that this ongoing process of globalization, with its dubious and sometimes disastrous effects on local society and culture, will make itself felt in Ethiopia as well. There is an evergrowing dependency of Ethiopia on external aid and donor country pressure in the face of its often ill-conceived development policies, a corresponding erosion of the sociocultural order, and an ongoing state neglect of local societies and their needs. Such factors make the impact of globalizing agents, including the IMF, World Bank, and the WTO regime, even more pervasive. ${ }^{7}$

These accelerated influences emanating from powerful external sources should not blind us to the fact that local societies have always been in contact with "the outside world," indeed were shaped by interaction with it. But the task of a comparative ethnography of cultural variation is to document and theoretically explain these existing local variations in a culture within the relevant historical-regional frameworks. It can thereby evoke more understanding and tolerance of diversity, because in a globalizing world these various forms will not simply whither away but become the issue of contestation and strife and thus have "policy relevance."

The present volume is only a beginning. The rich ethnographic diversity of the south needs continued scholarly exploration, recognition, and 
also respectful treatment. One ultimate aim of social science can be to facilitate dialogue and exchange between southern groups ${ }^{8}$ in the new era of ethno-federal politics and huge socioeconomic challenges. At present one can note quite disturbing political developments in the country, a relentless onslaught of commercially geared "globalization" processes-especially mass tourism, with its commodifying approach and commercial farming at the expense of peasants and pastoralists' land rights-as well as the top-down, so-called development schemes of both state and "donor country" institutions. These processes make a proper historical ethnography and a balanced scientific attention to the cultural and ethnic variety of Ethiopia-not only the south-all the more urgent. Such research is especially relevant, not primarily as a "history of the south" to fill in the lesser known aspects of the public record on Ethiopia, but as a contribution to address general questions in the study of culture and human behavior, as posed in anthropology as a transcultural comparative social science.

I express the hope that these papers inspire other researchers-both Ethiopians and foreigners in a fruitful, critical dialogue-to pursue comparative work on southern Ethiopia, either in the field through original research, or at the desk on the basis of the many published case studies available. Last but not least, I sincerely thank the contributors for their cooperation and patience in bringing out this volume.

\section{Notes}

1. See also my survey article (Abbink 1992a) on past anthropological work on southern Ethiopia.

2. Some examples are in the works of N. Sobania (1980) and G. Schlee (1989).

3. Of the participants, E. Watson, J. Lydall, and J. Abbink did not offer papers to be included in this collection.

4. See also Harris's excellent book Theories of Culture in Postmodern Times (1999).

5. The concept of generative mechanism is central in the emerging epistemological tradition of critical realism, an approach that has as one of its aims to bridge the explanatory gaps between "structure" and human "agency" (see Archer et al. 1998; López and Potter 2001).

6. The policy insisted on a "common language" for educational purposes called Wogagoda, a composite of Wolaitta, Gamo, Gofa, and Dawro). This was vehemently rejected by the Wolaitta (prominent among them the 
schoolteachers and pupils), and led to powerful demonstrations bloodily suppressed in late 1999 in Soddo (Wolaitta), with at least five people killed. In a rare move, the government subsequently gave in, abolished the plans, and gave the Wolaitta people their own administrative zone in 2000. Tensions, however, have emerged between various Gamo, Dawro, Dorze, and Wolaitta groups. See also the article by Data De'a, in this volume.

7. For some disturbing developments see Stiglitz, "The IMF Ravages Developing Countries, Ethiopia is the Proof" (2002), Chossudovsky, "Sowing the Seeds of Famine in Ethiopia" (2000), and Kirby, "Progress 'Undermines African Cultures"' (2002).

8. A remarkable example of such an effort is the founding of the South Omo Research Center (SORC) in the town of Jinka. The SORC, which combines research and local community functions, was the initiative of Professor Ivo Strecker of Mainz University.

\section{References}

Abbink, Jon. 1992a. Anthropological and Ethno-Historical Research on South-West Ethiopia: The Need for Integrative Synthesis. Bulletin de la Maison des Etudes Ethiopiennes 1: 22-44.

- 1992b. An Ethno-Historical Perspective on Me'en Territorial Organisation (Southwest Ethiopia). Anthropos 86: 351-64.

- 1993. Ethnic Conflict in the "Tribal" Zone: The Dizi and Suri in Southern Ethiopia. Journal of Modern African Studies 31, no. 4: 675-83.

Almagor, Uri. 1989. The Dialectic of Generation Moieties in an East African Society. In The Attraction of Opposites: Thought and Society in the Dualistic Mode, edited by David Maybury-Lewis and Uri Almagor, 143-70. Ann Arbor: University of Michigan Press.

Archer, Margaret; Roy Bhaskar; Andrew Collier; Tony Lawson; and Alan Norrie, eds. 1998. Critical Realism: Essential Readings. London and New York: Routledge.

Barnard, Alan. 1992. Hunters and Herders of Southern Africa: A Comparative Ethnography of the Khoisan Peoples. Cambridge: Cambridge University Press.

Barth, Fredrik. 1975. Ritual and Knowledge among the Baktaman of New Guinea. Oslo: Universitetsforlaget.

- 1987. Cosmologies in the Making: A Generative Approach to Cultural Variation in Inner New Guinea. Cambridge: Cambridge University Press. 
- 2002. An Anthropology of Knowledge. Current Anthropology 43, no. 1: 1-18.

Chossudovsky, Michel. 2000. Sowing the Seeds of Famine in Ethiopia. The Ecologist, September. Also at http://www.globalresearch.ca/articles/ CHO109B.html.

Donham, Don; Wendy James; Eisei Kurimoto; and Alessandro Triulzi, eds. 2002. Remapping Ethiopia: Socialism and After. Oxford: James Currey; Addis Ababa: Addis Ababa University Press; Athens, Ohio: Ohio University Press.

Driver, Harold E. 1973. Cross-Cultural Studies. In A Handbook of Method in Anthropology, edited by Raoul Narroll and Ronald Cohen, 327-67. Garden City, N.Y.: Natural History Press.

Geschiere, Peter; and Birgit Meyer, eds. 1999. Globalization and Identity: Dialectics of Flows and Closures. Oxford: Blackwell.

Gingrich, André; and Richard G. Fox, eds. 2002. Anthropology by Comparison. London and New York: Routledge.

Haberland, Eike. 1963. Galla Süd-Äthiopiens. Stuttgart: W. Kohlhammer Verlag.

Harris, Marvin. 1994. Cultural Materialism Is Alive and Well and Won't Go Away until Something Better Comes Along. In Assessing Cultural Anthropology, edited by Robert Borofsky, 62-76. New York: McGrawHill.

- 1999. Theories of Culture in Postmodern Times. Walnut Creek, London, and New Delhi: Altamira Press.

Herzfeld, Michael. 1992. The Social Production of Indifference: Exploring the Symbolic Roots of Western Bureaucracy. Chicago and London: University of Chicago Press.

Hinnant, John. 1989. Ritual and Inequality in Guji Dual Organization. In The Attraction of Opposites: Thought and Society in the Dualistic Mode, edited by David Maybury-Lewis and Uri Almagor, 57-76. Ann Arbor: University of Michigan Press.

Jensen, A. E. 1953. Dualsysteme in Nordost Afrika. Anthropos 48: 738-59.

Jorgensen, Joseph G., ed. 1974. Comparative Studies by Harold Driver and Essays in his Honor. New Haven, Conn.: HRAF Press.

Kirby, Alex. 2002. Progress "Undermines African Cultures." http:// news.bbc.co.uk/1/hi/sci/tech/1975359.stm. 
Knauft, Bruce R. 1993. South Coast New Guinea Cultures: History, Comparison, Dialectic. Cambridge: Cambridge University Press.

Kuper, Adam. 1982. Wives for Cattle. London: Routledge and Kegan Paul.

- 2000. Culture: The Anthropologist's View. Cambridge: Harvard University Press.

López, José; and Garry Potter. 2001. After Postmodernism: An Introduction to Critical Realism. London and New York: Athlone Press.

Nash, June C. 2001. Mayan Visions: The Quest for Autonomy in an Age of Globalization. London and New York: Routledge.

Obeyesekere, Gananath. 1992. The Apotheosis of Captain Cook: European Mythmaking in the Pacific. Princeton, N.J.: Princeton University Press.

Ohnuki-Tierney, Emiko. 1990. Culture Through Time: Anthropological Approaches. Stanford, Calif.: Stanford University Press.

Orent, Amnon. 1970. Dual Organizations in Southern Ethiopia: Anthropological Imagination or Ethnographical Fact? Ethnology 9, no. 3: 228-33.

Pankhurst, Alula. 2000. Globalization and the Survival of Craftwork in Ethiopia. Ethiopian Development Forum 1, no. 1: 47-66.

Piot, Charles L. 2000. Remotely Global: Village Modernity in West Africa. Chicago and London: University of Chicago Press.

Popp, Wossen M. 2001. Yem, Janjero oder Oromo? Die Konstruktion ethnischer Identität im sozialen Wandel. In Integration durch Verschiedenheit: Lokale und Globale Formen Interkultureller Kommunikation, edited by Alexander Horstmann and Günther Schlee, 367-404. Bielefeld: Transkript Verlag.

Rivière, Peter. 1984. Individual and Society in Guyana Societies. Cambridge: Cambridge University Press.

Sahlins, Marshall. 1985. Islands of History. Chicago and London: University of Chicago Press.

- 1995. How "Natives" Think: About Captain Cook, for Example. Chicago and London: University of Chicago Press.

- 1999. What is Anthropological Enlightenment? Some Lessons of the Twentieth Century. Annual Reviews in Anthropology 28: i-xxiii. 
Schlee, Günther. 1989. Identities on the Move: Clanship and Pastoralism in Northern Kenya. Manchester: Manchester University Press.

Simonse, Simon. 1992. Kings of Disaster. Leiden: E. J. Brill.

Sobania, Neil W. 1980. The Historical Tradition of the Peoples of the Eastern Lake Turkana Basin, c. 1840-1925. Ph.D. diss., University of London.

Sperber, Dan. 1986. Anthropology and Psychology: Towards an Epidemiology of Representations. Man 20, no. 1: 73-89.

Stiglitz, J. 2002. The IMF Ravages Developing Countries, Ethiopia is the Proof. http://www.waltainfo.com/Profile/Infoarticles/2002/april/ article3.htm.

Straube, Helmut. 1957. Das Dualsystem und die Halaka-Verfassung der Dorse als alte Gesellschaftsordnung der Ometo-Völker Süd-Äthiopiens. Paideuma 4: 342-53.

Tronvoll, Kjetil. 2001. Voting, Violence and Violation: Peasant Voices on the Flawed Elections in Hadiya, Southern Ethiopia. Journal of Modern African Studies 39, no. 4: 697-716.

Young, John W. 1999. Along Ethiopia's Western Frontier: Gambella and Benishangul in Transition. Journal of Modern African Studies 37, no. 2: 321-46. 